\title{
Jan Czochralski, the pioneer of crystal research
}

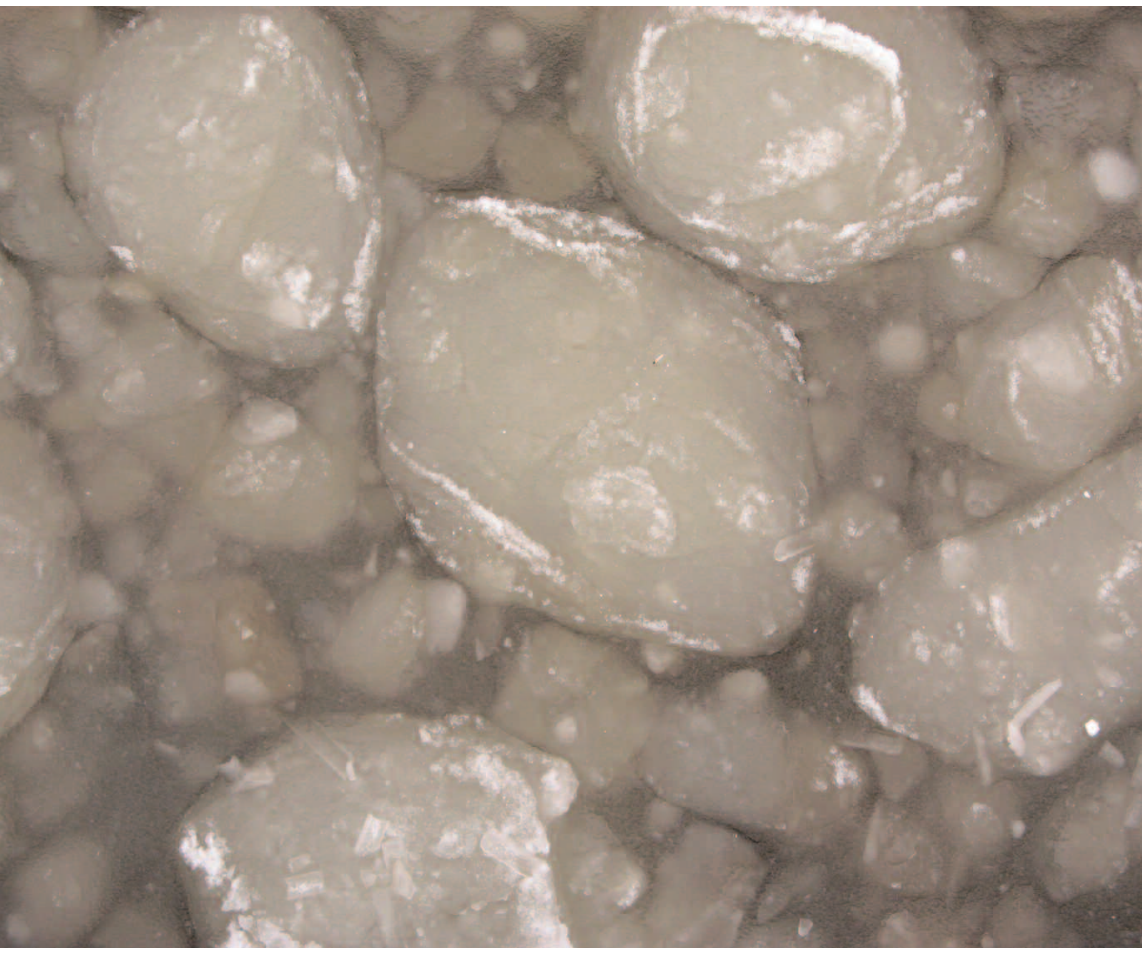
See water, with some crystals and close-packed configuration
J an Czochralski (1885-1953) was born in Kcynia near Bydgoszcz (Kujawy and Pomorze district in Poland), roughly halfway between Warsaw and Berlin. His seminal work on metallic single crystals and their growth rates was published in Zeitschrift für physikalische Chemie, received for publication in August 1916, but not published until two years later [2]. This paper was an example - rarely seen these days of being precise and specific in presenting research achievements. In just three pages the author reported on his new findings, namely, that a method of pulling metallic single crystals had been discovered in terms of their growth rates (and nucleation-promoting ionic additives), and that it had been applied for testing crystal growth of three metals: $S n, P b$, and $Z n$. This raised, in fact, great admiration both in Poland and abroad [1,3-5]. As a consequence of this work, he is still recognized as one of the founders of today's crystal-growth technology and research [3], although originally his method was rather elaborated for the three metals mentioned above.

\section{Crystal growth}

While performing research on crystal growth and its theroretical foundations, I was often surprised by Czochralskis quite unexpected interests and connotations

\author{
— Adam Gadomski - agad@utp.edu.pl \\ DOI: $10.1051 /$ epn/2011504 \\ Department of Modeling of Physicochemical Processes \\ - Institute of Mathematics and Physics \\ - University of Technology and Life Sciences \\ Bydgoszcz, Poland
}

\begin{abstract}
Not only was Jan Czochralski the first to propose a method of pulling metallic single crystals from a melt, and to successfully quantify their growth rates, he passionately devoted his entire productive life to crystal research, material science and chemistry, to name only a few areas of his expertise [1].
\end{abstract}

in many, not entirely technological, aspects of crystal growth. They were mostly addressed in terms of solidstate type (poly)crystalline forms [3], see Figs. 1 and 2. His interests involved not only initial single-crystal growth but also the emergence of "nonequilibrium" polycrystals, as well as their recrystallization [1-3]. As one may know, both kinds of processes are based on one-seed and many-seeds nucleation and growth-phase transformation rules [5]. However, they rely on different competition behaviour of the feeding material, coming either from a solution or from some melt $[4,5]$. The basic difference concerning an (un)even distribution of the feeding material is illustrated schematically in Figs. 1a and $1 \mathrm{~b}$. These figures also illustrate possible differences in output morphologies, depending on the material-involving competitive nuclei. This results ultimately in crystalline polymorphic forms [6].

Which of the present-time developments are, in my personal opinion, the most important ones when seen in the context of Czochralski's well-known [1-5] accomplishments? It seems to me that there are at least two: (i) The solid-liquid complex crystal-interface dynamics, in general characteristic of (non)linear morphological instabilities and primarily resulting from concerted actions of mass- and thermal diffusion fields [6]; (ii) 
Crystal growth of colloid and (bio)macromolecular non-Kossel type systems. These are complex structures, with serveral crystallizing large molecules per unit cell in non-equivalent positions [7], see Fig. 2.

\section{Crystal-liquid interface}

Concerning point (i), it has been proposed to solve this analytically and numerically in terms of the Stefan moving-boundary (diffusion) problem. This describes a diffusive mass and/or heat transport accross a crystalliquid (originally: ice-water) interface [8]. Many attempts have been made since the early 1960s to achieve a robust nonlinear extension of the morphological, though originally linear, crystal-involving (in)stability analysis by Mullins and Sekerka (MS) $[4,5]$. The MS problem was originally treated as being driven either by a concentration gradient or by undercooling [5]. The result of the instability analysis of the growth process has been a square-root-of-time evolution of the sphere radius, as well as an exponential time decay of its crystal-surface perturbation amplitude [4]. However, none of the attempts were able to reproduce an accepted universal and robust solution to the problem of crystal-phase advancement into its ambient (solution/melt) phase, irrespective of the fact that the phenomenon had always been proposed to be diffusion-controlled [4]. Very recently, it has become clear that, for instance, (bio)macromolecular crystal formations cannot follow exclusively the diffusion-limited path. In fact, experimental evidence shows quite often a constant growth rate [5]. This requires a model of massor molecular-aggregates-involving incorporation in versatile near-crystal-surface stable conditions. Such a model, while based on minimal entropy-production rate [7], is also benchmarked by the complex problem of interface-controlled growth. The resulting growth rate is often analogous to the MS instability modus to a reasonable extent $[4,5]$. A careful analysis of such

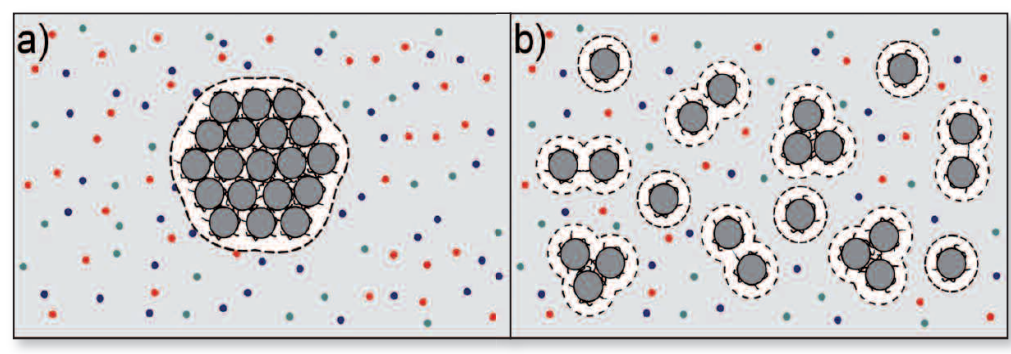

$\Delta$ FIG. 1: Schematics of a single "hexagonal" crystal growth for two cases. Panel a): The crystal welcomes the addition of atoms, ions or molecules which are depicted as point-like, coloured (incoming) objects. They represent, for example, different (macro)ionic species incorporated in a crystal-growth form when emerging from a solution of elecrolytic nature [6]. Panel b) represents quite the same case (be it immature and non-hexagonal) but now involving many randomly distributed nuclei that steadily try to compete for the coloured point-like (macro)ionic material, thus depleting the adjacent (white) regions. The shaded background represents an aqueous solution, whereas the coloured point-like objects are protein macroions (blue), and ionic precipitants, such as those coming typically from $\mathrm{NaCl}$ dissociation (in red and green, respectively), which serve to facilitate the nucleation. If the incorporation is successful, the built-in soft material becomes eventually dark and is drawn towards the round, grey objects [7]. (Courtesy of J. Siodmiak, Bydgoszcz.)

interfacial stochastic dynamics may inevitably lead to (non)equilibrium, mature-stage conditions of the cessation-to-growth. These conditions state that a crystal is formed upon some prevailing, temporary but algebraic velocity-time correlations, pointing to a flicker (i.e., quenched) noise, residing in the interfacial zone. Otherwise, a disorderly scenario, pointing to uncorrelated (thermal) noise, prevails over its order-promoting and fairly self-organising counterpart [7].

\section{Colloid and (bio)macromolecular systems}

Concerning point (ii): It would have been a dream of Czochralski to have the privilege of tackling such problems (see pp. 47-66 by A.A. Chernov in [5]), including utilisation of colloid stability (e.g., in late W.A. Tiller's works [5]). Why? First, in order to verify his expectation that biomolecules, such as lysozymes [6-7], would form single non-Kossel crystals of many polymorphic forms [6]. Second, to show that there exists a certain, though limited, structural order in their morphologies [5].

V FIG. 2: Cartoon of a single terrace of a model spiral-grown crystal (see drawing on the right) of width $N \sim \lambda_{0}$ onto which two different types of virtual constituents of the crystal are shown: hydrophobic (white balls) and hydrophilic polar (dark balls). They perform both translational and rotational random motions, preferentially along the blue-coloured terrace's interior, but stay between the red kinks, equipped with temperature-agitated Ehrlich-Schwöbel barriers [4-7]. The spiral growth illustrated on the right is often referred to as the Burton-Cabrera-Frank (BCF) mode. (Courtesy of J. Siodmiak, Bydgoszcz; see also http://arxiv.org/abs/1103.4551.)
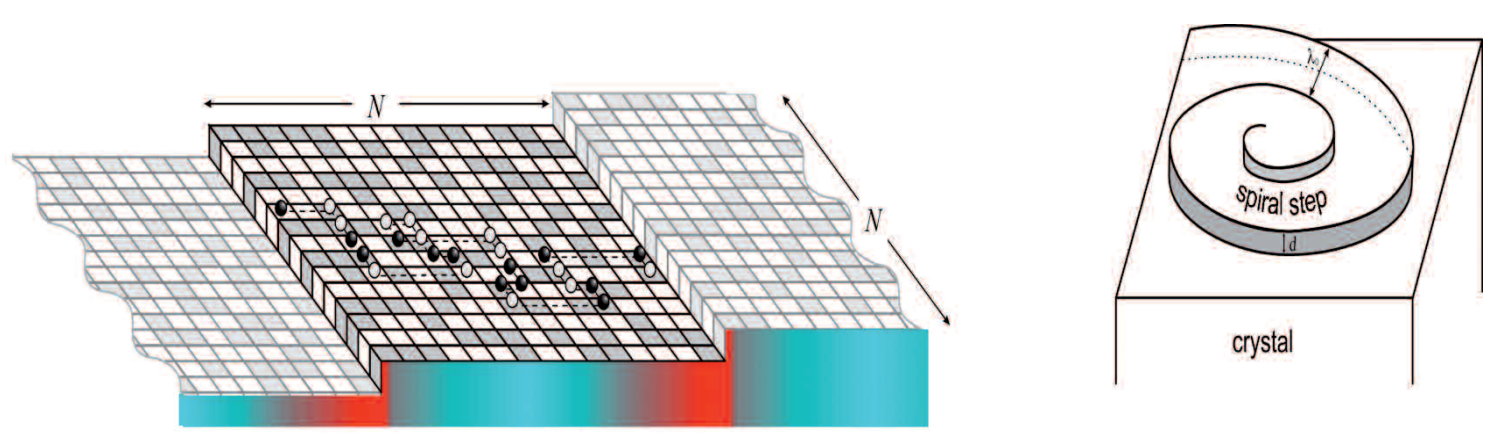


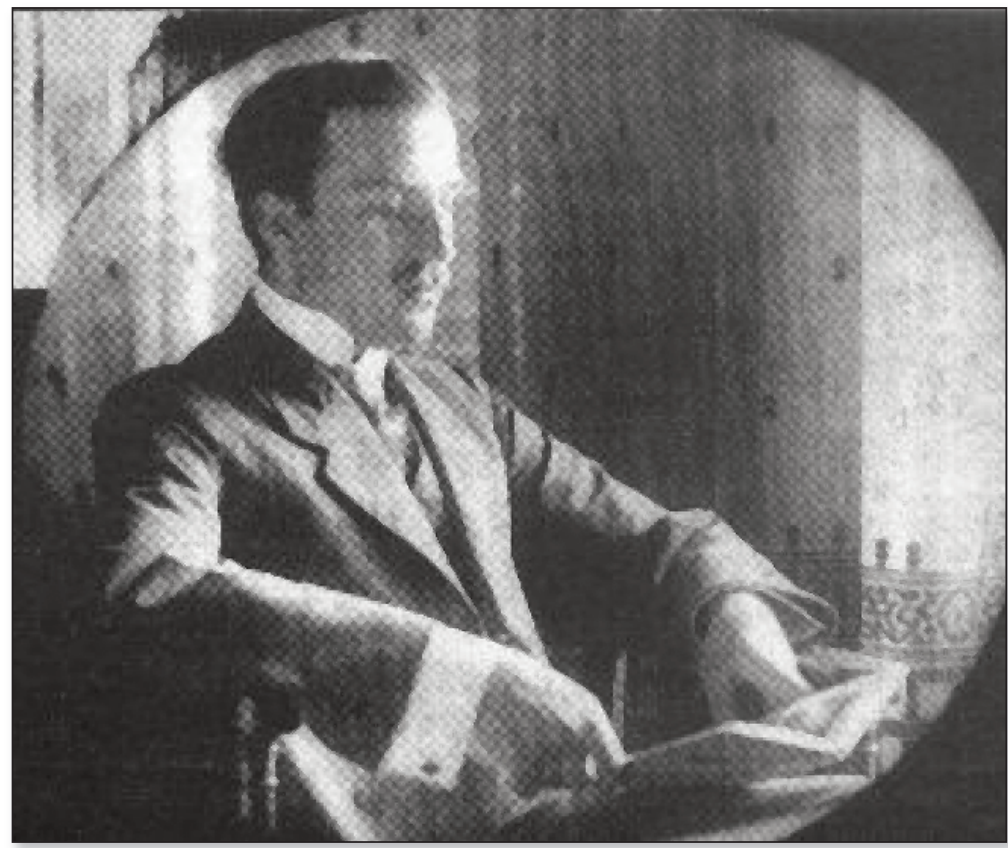

$\triangle$ FIG.3: $\quad$ Third, to prove that the principal model of dislocationMiddle-aged Jan Czochralski, patiently writing down his research notes.

(Courtesy of

Z. Czochralska, Kcynia.) driven BCF growth [5-7] is useful for performing at least computer simulations designed for soft-matter crystal formation (see [6-7], and references therein). Next, that the cumbersome problem of crystal-interface involvement can be treated as being separated into working schemes of practical interest, especially the ones concerning the so-called crystal-growth layer [9] or active interfacial zone [5]. In this field, the future undoubtedly belongs to computer simulations, judiciously supported by powerful physical concepts such as those of thermodynamic-kinetic nonequilibrium and mesoscopic nature [7]. Proposals which are based on experimentally well-motivated scenarios and the ones correctly addressing the involving fields' interplay are worth entering. Especially those proposals will deserve special attention which follow the intermingled thermal and electrostatic, as well as hydrophobic pathways of the involved spatio-temporal competing fields that are located within the interface [9]. Protein databases, such as the $P D B$ [6], will immensely support this way for crystallizing new protein and colloid species.

It should be concluded that future progress in this field would be impossible without including both Czochralski and his CZ method $[1,3,5]$ in our worldwide technicalknowledge accumulating database $[1,5,9]$. This is especially worth mentioning in the year in which almost a century has passed since he decided to submit his practical and incredibly useful results, which established the experimental foundations for the new age of silicon-based high technology $[1,2,3,5,8]$. Each of us greatly benefits, directly or indirectly, from his inheritance. Therefore, it seems right to recognize his valuable work, and once again recall abbreviations such as $C Z$, tightly accompanied by the others, namely, BCF and/or MS [5].

\section{Czochralski and World War II}

Czochralski's political attitude during World War II was sometimes questioned, especially since he conducted research in an institute of Warsaw University of Technology (WUT) founded by German occupants. However, the doubts formerly expressed about this in $[1,3]$ must be radically changed due to the revelation of some important facts. A thorough investigation of the Polish state archives [10], covering personal political activities of those times, rediscovered him as a person who cooperated tightly with the Polish Underground State Army (the so-called Armia Krajowa). In fact, he made this military organization aware of some German technical facilities, which were hidden near Warsaw and somewhere abroad. Based on this very recent finding [10], the Senat of WUT rehabilitated him ultimately as WUT professor on its meeting on June 29 , 2011. Thus, after 66 years $[1,4]$ of reputation loss as a Polish university professor, who seemed to have collaborated with Germany during World War II, this supposition has very likely been refuted [10].

\section{Acknowledgement}

My deepest thanks go to Dr. Teresa Saskowska (Sniadecki Hospital in Znin) for drawing my attention to Ref. [10].

\section{About the author}

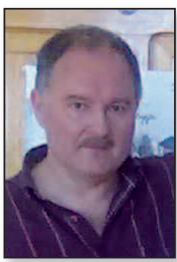

Adam Gadomski is titular professor of physics at the University of Technology \& Life Sciences, Bydgoszcz, Poland. $\mathrm{He}$ is head of the department of modeling of physicochemical processes, and specialized in statistical physics and (soft) condensed matter theory. For further details, see http://who.is.who.physics.pl/ index.php?id=00498.

\section{References}

[1] P.E. Tomaszewski, Jan Czochralski and His Method, Institute of Low Temperature and Structural Research P.A.S. and Atut Publishing House, Wroclaw-Kcynia, 2003, in Polish.

[2] J. Czochralski, Z. Phys. Chem. 92, 219 (1918), in German

[3] A. Gadomski, Europhysics News 35/1, 20 (2004).

[4] R.F. Sekerka, Cryst. Res. Technol. 40, 291 (2005).

[5] R.S. Feigelson (ed.), 50 Years Progress in Crystal Growth. A Reprint Collection, Elsevier, Amsterdam, 2004.

[6] J. Siodmiak, A. Gadomski, J. Noncryst. Solids 354, 4221 (2008).

[7] J. Siodmiak, I. Santamaria-Holek, A. Gadomski, J. Chem. Phys. 132,195103 (2010)

[8] J. Strnad, Europhysics News 42/2, 17 (2011).

[9] P.G. Vekilov, J.I.D. Alexander, Chem. Rev. 100, 2061 (2000).

[10] P. Cieslinski, Gazeta Wyborcza.p/ 163, 18-19 (2011); a link in Polish available at http://m.wyborcza.pl/wyborcza/ 1,105226,9953629,Sceny_z_zycia_patrioty_ktorego_ uznano_za_zdrajce.html. 